\title{
Acute inflammatory polyradiculoneuropathy following type A viral hepatitis
}

\author{
C. L. W. JOHNSTON* \\ M.A., M.R.C.P.
}

M. SCHWARTZ $\dagger$
M.D.

\author{
M. H. WANSBROUGH-JONES* \\ M.Sc., M.R.C.P.
}

\section{*Communicable Diseases Unit, St George's Hospital, London SW17 0QT, and †Department of Neurology, Atkinson Morley's Hospital, London SW20 ONE}

\begin{abstract}
Summary
A case is described of acute inflammatory polyradiculoneuropathy (Guillain-Barré syndrome) following a recent infection with type $A$ viral hepatitis. This association has not previously been reported. The neurological disturbance was unusual in being predominantly sensory.
\end{abstract}

\section{Case report}

A previously fit 37 -year-old male presented with a 2-week history of lethargy and malaise. For one week he had noticed yellow sclerae and over 5 days developed a progressive weakness and clumsiness initially in the upper limbs but spreading to involve the lower limbs so that he was unable to walk unaided. He had associated numbness and paraesthesiae in the neck, hands and feet.

There was no history suggesting contact with hepatitis. His alcohol intake was small and his only recent medication had been a proprietary antacid.

At the age of 12 years, in association with chickenpox, he had a similar episode of ataxia and paraesthesiae which resolved slowly over one year. In 1974 he was treated for tuberculous lymphadenitis. At the time of diagnosis he was found to be areflexic with an equivocal Romberg's test but no other sensory or motor abnormalities were noted. $\mathrm{He}$ was treated with ethambutol, isoniazid and pyridoxine. The next year areflexia was found at an insurance medical examination and he was referred to a neurologist who found no other abnormalities.

On admission he was icteric but there were no other signs of liver disease and he was apyrexial. Positive neurological findings were reduced tone but normal power in all limbs, vibration sense absent in the limbs and trunk, proprioception impaired in all limbs and a severe sensory ataxia. Light touch and pin-prick were impaired in a glove-and-stocking distribution, and tendon reflexes absent. Plantar responses were flexor.
Laboratory tests showed normal $\mathrm{Hb}$, WBC and plasma urea and electrolytes. Bilirubin was $72 \mu \mathrm{mol} / \mathrm{l}$ (normal $<20$ ), alanine transaminase 617 i.u./l (normal <35), alkaline phosphatase 198 i.u./l (normal < 100). Paul-Bunnell (monospot) and hepatitis B surface antigen were negative. Antihepatitis A virus IgM antibody was positive, confirming a recent infection.

Serum $B_{12}$, folate, copper and caeruloplasmin, and VDRL tests were negative. Anti-mitochondrial, smooth muscle and DNA binding antibodies were negative. No rise was detected in paired sera antibody titres to Epstein-Barr, cytomegalo- or in varicella zoster viruses. Complement series was normal. No circulating immune complexes were detected by a Clq binding assay. HLA status was A1, A9, B37, B40.

The cerebro-spinal fluid, examined 9 days after the onset of neurological symptoms, was sterile with a normal glucose, less than 3 white cells and protein content of $29 \mathrm{~g} / \mathrm{l}$. Electromyography showed absent sensory action potentials in both nerves tested (right sural and right median) with a 4-fold increase in stimulation threshold. Motor nerve conduction velocities were normal in all nerves tested. $F$ responses were slowed in the right lateral popliteal and right ulnar nerves with prolongation of distal latency in the right medial popliteal nerve.

After 2 weeks he was anicteric and the liver function tests had improved. At that time he was still areflexic but was able to walk with only a mild sensory ataxia. Repeat electromyography one week later showed normal motor nerve conduction velocities, $F$ responses and sensory potentials in all nerves tested. Six-month follow-up revealed little change in symptoms or physical signs.

\section{Discussion}

Guillain-Barré syndrome is an acute inflammatory polyradiculoneuropathy which usually presents with 
motor weakness but occasionally sensory involvement may predominate (Arnason, 1975). The diagnosis is essentially clinical depending on recognition of a progressive symmetrical polyradiculopathy with or without a history of preceding infection. The CSF protein is usually elevated without an accompanying cellular response but the CSF can often be normal in the early stages and in some cases it remains so (Masucci and Kurtzke, 1971).

The patient described had an acute polyradiculoneuropathy and nerve conduction studies demonstrated a predominantly sensory neuropathy with abnormal F responses. Prolonged distal latency and slowed $F$ responses with normal motor nerve conduction velocities are the characteristic electromyographic features of Guillain-Barré syndrome (Kimura, 1978).

Guillain-Barré syndrome is often preceded by an acute viral infection and an association with acute hepatitis has been recognized (Leschner, 1944; Asbury, 1975). The aetiology of the hepatitis was not identified in any of these cases but GuillainBarré syndrome associated with acute hepatitis due to Epstein-Barr virus (Grose and Feorino, 1972), cytomegalovirus (Leonard and Tobin, 1971) and hepatitis B virus (Niermeijer and Gips, 1975) have all been recorded. This is the first time that acute hepatitis A virus infection has been positively identified as the preceding aetiological factor.

Guillain-Barré syndrome following varicella zoster is well recognized (Miller, Stanton and Gibbons, 1956). From the patient's own description his illness at the age of 12 years appeared to be a similar episode of inflammatory polyradiculoneuropathy. Recurrent attacks are said to occur in about 3\% and may appear after an interval of many years. Although preceding factors may be different, the clinical syndrome is usually similar except that sensory involvement is more common and the prognosis for complete recovery worse (Arnason, 1975). Relapsing polyneuritis is said to differ from the acute Guillain-Barré syndrome in that it is often responsive to corticosteroid therapy (Prineas and McLeod, 1976) and it is associated with the HLA antigens AW30 and AW31 (Stewart et al., 1978).
This lends support to the concept that there is a inherited susceptibility to an auto-immune neurit $\$$ which can be triggered by different viral stimuli: However, the patient reported did not possess th $\overrightarrow{\bar{t}}$ described HLA antigens and he rapidly improveg without corticosteroid therapy.

With the advent of accurate serological identif cation of acute hepatitis A virus infection, it shoule be considered in the differential diagnosis when acue inflammatory polyradiculoneuropathy is associated with abnormal liver function tests.

\section{Acknowledgments}

We are grateful to Dr Philip Mortimer and staff at th Viral Reference Laboratory, Colindale, for estimating the hepatitis A virus IgM antibody.

\section{References}

ARnason, B.G.W. (1975) In: Peripheral Neuropathy (Ed by Dyck, P.J., Thomas, P.K. \& Lambert, E.H.), Vol. 2, p. $11 \notin$ W. B. Saunders Co., Philadelphia.

Asbury, A.K. (1975) In: Peripheral Neuropathy (Ed by Dych P.J., Thomas, P.K. \& Lambert, E.H.), Vol. 2, p. 99? W. B. Saunders Co., Philadelphia.

Grose, C. \& Feorino, P.M. (1972) Epstein-Barr virus an Guillain-Barré syndrome. Lancet, ii, 1285.

Kimura, J. (1978) Proximal versus distal slowing in m\&̊ore nerve conduction velocities in the Guillain-Barré syndrome Annals of Neurology, 3, 344.

LeONARD, J.C. \& ToBIN, J.O'H. (1971) Polyneuritis associäeg with cytomegalovirus infections. Quarterly Journal of Medicine, 40, 435.

LESCHNER, F. (1944) The nervous complications of infectious hepatitis. British Medical Journal, 1, 554.

MASUCCI, E.F. \& KURTZKE, J.F. (1971) Diagnostic criteri for the Guillain-Barré syndrome. Journal of Neurologicat Science, 13, 483.

Miller, H.G., Stanton, J.B. \& Gibbons, J.C. (195\%) Para-infectious encephalomyelitis and related syndromes Quarterly Journal of Medicine, 25. 455.

NIERMEIJER, P. \& GIPS, C.H. (1975) Guillain-Barré syndromè in acute $\mathrm{Hb}_{\mathrm{s}} \mathrm{Ag}$-positive hepatitis. British Medical Journa? 4, 732.

Prineas, J.W. \& MCLeod, J.G. (1976) Chronic relapsing polyneuritis. Journal of Neurological Science, 27, 427.

Stewart, G.J., Pollard, J.D., MCLeod, J.G. \& Wolnizeri C.M. (1978) HLA antigens in the Landry-Guillain-Barre syndrome and chronic relapsing polyneuritis. Annals of Neurology, 4, 285. 